\title{
LAS CÉLULAS NEUROLÓGICAS Y SU INTERFAZ EN EL PROCESO DE APRENDIZAJE DE LOS SERES VIVOS
}

\author{
José Américo de Souza GAIA ${ }^{1}$; Carolina Lima Bezerra GAIA ${ }^{2}$; Erick John Batista MOURA ${ }^{3}$; \\ Gil Dutra FURTADO ${ }^{4}$; Carlos Alberto ISAZA ${ }^{5}$
}

\footnotetext{
${ }^{1}$ Doctor en Ciencias Policiales de Seguridad y Orden Público y Esp. En Administración Policial. Ingeniero Agrónomo/Universidade Federal do Acre (UFAC), Brasil. E-mail: americogaia@ hotmail.com

${ }^{2}$ Especialista en Gestión de Proyectos. Bióloga/UFAC, Brasil. E-mail: carolina.gaia@gmail.com

${ }^{3}$ Especialista en Seguridad del Trabajo. Ingeniero Agrónomo/Universidade Federal da Paraíba (UFPB), Brasil. E-mail: agro.erick@hotmail.com

${ }^{4}$ Estudiante de Medicina Veterinaria/Centro Universitário Maurício de Nassau (UNINASSAU/PB), João Pessoa, Brasil. Ingeniero Agrónomo/UFPB; Doctor en Psicobiología/Universidade Federal do Rio Grande do Norte (UFRN), Brasil; Agrónomo-Socio de la Cooperativa de Agronegocio (COOPAGRO), Brasil. E-mail: ghdfurtado@hotmail.com

${ }^{5}$ Graduação en Contaduría Pública en Universidad del Valle (), Colombia; Mestrando en Desenvolvimiento e Medio Ambiente (PRODEMA)/UFPB; E-mail: carlos0isaza@gmail.com
}

Resumen. Este trabajo tiene como objetivo promover la comprensión de la interfaz del papel de las células neurológicas con el proceso de aprendizaje de los individuos. La investigación está estructurada en cuatro tópicos de discusión: Comprensión de las estructuras básicas del sistema nervioso, fisiología e morfología de las células neurológicas, cognición y tareas cognitivas, neuroplasticidad y rehabilitación. El artículo hace una breve revisión de la literatura, permeando el aspecto funcional y biológico del sistema nervioso y células neurológicas, discutiendo los aspectos y procesos que traducen la cognición y el desarrollo cognitivo y sus mecanismos de aprendizado, convergindo para la descubierta de la neuroplasticidad que apunta posibilidades de terapias restauradoras de la capacidad cognitiva. El estudio demuestra que es de suma importancia la ampliación del debate e investigación científica destinada a los dominios del conocimiento de los aspectos biológico, neurológico y neurosicológico de la capacidad de aprendizado, dada la importancia de ese conocimiento en la proposición de soluciones y terapias destinadas al tratamiento de patologias que presentan pérdidas cognitivas leves y severas, comprometedoras de la capacidad global y cualidad de vida.

Palabras clave: Células Neurológicas; Sistema Nervioso; Cognición; Desarrollo Cognitivo; Plasticidad Cerebral; Neuroplasticidad.

\section{THE NEUROLOGICAL CELLS AND THEIR INTERFACES IN THE LIVING BEINGS LEARNING PROCESS}


Abstract. This work aims to promote understanding of the role of neurological cells with the learning process of the individual interface. The research is divided into four discussion topics: understanding of the basic structures of the nervous system; physiology and morphology of neurological cells; cognition and cognitive tasks; neuroplasticity and rehabilitation. The article makes brief review of permeating literature by the functional and biological aspects of the nervous system and neurologias cells, discussing the issues and processes that translate cognition and cognitive development with and their learning mechanisms, converging to discovery of neuraplastidade pointing therapies possibilities restored cognitive ability. The study demonstrates that it is extremely important to expand the debate and scientific research for the fields of knowledge about the biological, neurological and neuropisicologico of learning ability, given the importance of this knowledge in proposing solutions and therapies for the treatment of pathologies have lost light and severe cognitive, compromising the overall capacity and quality of life.

Keywords: Neurological Cells; Nervous System; Cognition; Cognitive; Brain Plasticity; Neuroplasticity.

\section{AS CÉlulas NeUROLÓgICAS E SUAS INTERFACES NO PROCESSO DE APRENDIZAGEM DOS SERES VIVOS}

Resumo. Este trabalho visa promover a compreensão do papel das células neurológicas com o processo de aprendizagem da interface individual. A pesquisa está dividida em quatro tópicos de discussão: compreensão das estruturas básicas do sistema nervoso; fisiologia e morfologia das células neurológicas; cognição e tarefas cognitivas; neuroplasticidade e reabilitação. $\mathrm{O}$ artigo faz uma breve revisão da permeação da literatura pelos aspectos funcionais e biológicos do sistema nervoso e neurológicas, discutindo os problemas e processos que traduzem o desenvolvimento cognitivo e cognitivo com seus mecanismos de aprendizagem, convergindo para a descoberta de possibilidades de terapias apontadas de neuroplastidade restaurada. O estudo demonstra que é de extrema importância ampliar o debate e a pesquisa científica para as áreas de conhecimento sobre o biológico, neurológico e neuropisicológico da capacidade de aprendizagem, dada a importância desse conhecimento em propor soluções e terapias para o tratamento de patologias que perderam a luz e cognitivo grave, comprometendo a capacidade global e a qualidade de vida.

Palavras-chave: Células Neurológicas; Sistema nervoso; Conhecimento; Cognitivo; Plasticidade Cerebral; Neuroplasticidade.

\section{INTRODUCCIÓN}

El proceso de aprendizaje ocurre a lo largo de la existencia de los seres vivos y la observación del comportamiento animal viene siendo el principal instrumento de ese proceso a lo largo de los años. El estudio del comportamiento animal presenta relevante contribución para el 
estudio del comportamiento humano, para las neurociencias, para el manejo del medio ambiente y de recursos naturales, educación y futuras generaciones. Según Snowdon (1999), el comportamiento es la ligación entre los organismos y el ambiente, entre el sistema nervioso y el ecosistema.

El estudio del comportamiento animal llevo a Darwin a concluir que cada especie es dotada de su propio conjunto de peculiaridades y patrones de comportamiento, de la misma forma que es dotada de sus propias características anatómicas. Las investigaciones de Charles Darwin sobre las expresiones de la emoción en animales, ejercieron respetable influencia sobre diversos psicólogos que estudian el comportamiento emocional humano. Para Snowdon (1999), los trabajos de Harry Harlow sobre el desarrollo social de los primates Rhesus y los de Overmier, Maier y Seligman sobre del desamparo aprendido, tuvieron fuerte influencia en las teorías de desarrollo infantil y en la psiquiatría.

Según Odum (1988), el comportamiento es un importante componente de compensación de los factores limitantes y reguladores del ambiente con relación al desarrollo ecotípico. Los organismos regulan los respectivos ambientes internos y microambientes externos por conducta o por fisiología. Tal adaptación diferencia el nicho ecológico de cada especie, que corresponde no solo al lugar donde vive, sino también a la forma como transforma energia, se comporta, responde a su ambiente físico, biótico y como altera el ambiente donde vive.

Ricklefs (1996) dice que nicho ecológico es la relación del individuo o de la populación con todos los aspectos de su ambiente, y de esa forma el papel ecológico de las especies dentro de la comunidad. Odum (1959) afirma que la posición de un organismo en un determinado ecosistema es resultante de sus adaptaciones estructurales, respuestas fisiológicas y comportamiento específico que pueden darse por adaptación o aprendizado.

A la luz de ese contexto surge la neurociencia como el estudio del sistema nervioso: su estructura, desarrollo, funcionamiento, evolución, relación con el comportamiento y la mente, y también sus alteraciones. El comportamiento animal y la neurociencia son herramientas integradas en el estudio de los proceso de aprendizaje, pues proveen bases teóricas importantes para la proposición de mecanismos neuronales, una vez que producen datos que posibilitan a los neurobiologos e investigadores en general, direccionar sus estudios y enfocarlos sobre estímulos relevantes, eligiendo respuestas igualmente relevantes. Así, para Snowdon (1999), varios experimentos y observaciones permitieron el uso de indicadores que posibilitaron la emersión de nuevos insights sobre las estructuras y funciones neuronales. 
Conforme a lo expuesto, muchos investigadores vienen proponiéndose a lo largo de los años, a comprender el comportamiento de los seres vivos y sus mecanismos de aprendizaje y su capacidad de adaptación, sin embargo, la cobertura de esos fenómenos pasa por la comprensión de las células neurológicas y sistema nervioso como un todo.

De esta forma, este trabajo tuvo como objetivo realizar una revisión de la literatura sobre las células neurológicas y su interfaz en el proceso de aprendizaje de seres humanos y animales, además, el trabajo pretende promover la comprensión de las estructuras básicas del sistema nervioso, fisiologia y morfologia de las células neurológicas, cognición y tareas cognitivas, neuroplasticidad y rehabilitación.

\section{Sistema Nervioso}

Varios autores como Capra (2006; 2012), Damásio (1996) y Cosenza y Guerra (2011), presentan la visión de que es necesaria la comprensión del funcionamiento del cerebro para establecer su relación con el aprendizaje. Una vez que las informaciones sensoriales son conducidas por medio de circuitos específicos al cerebro, donde serán procesadas generando una respuesta de reconocimiento del estímulo sensorial al que está sucediendo en el ambiente, con eso, el cerebro produce respuestas de interacción necesarias a la sobrevivencia de los individuos. Por lo tanto, sigue a continuación una breve discusión sobre las estructuras y dinámica funcionales del sistema nervioso.

El sistema nervioso es constituido basicamente de dos partes fundamentales que son el sistema nervioso central (SNC) y el sistema nervioso periférico (SNP). El sistema nervioso central es la porción responsable por el atendimiento de los estímulos de comando y desencadenando así respuestas para cada estímulo recibido. El sistema nervioso central, constituido por el encéfalo y por la médula espinal y por el sistema nervioso periférico (nervios craneanos y raquideanos). El encéfalo es formado por el cerebro, cerebelo, bulbo, que son elementos importantes en la constitución nerviosa de nuestro organismo. El sistema nervioso central es el responsable por el comando de varias funciones en nuestro cuerpo, siendo primordial para su buen funcionamiento. El cerebro es responsable por la percepción de los diferentes estímulos externos a través de los sentidos, de la inteligencia y de la memoria (FAVARETTO; MERCADANTE, 2003).

A seguir, un breve análisis de la constitución del sistema nervioso central. El encéfalo está localizado en la caja craneana y presenta tres órganos principales: el cerebro, el cerebelo y el tronco encefálico; Cerebro es el órgano más importante del sistema nervioso, pues ocupa la mayor parte del encéfalo, está dividido en dos partes simétricas: el hemisferio derecho y el 
hemisferio izquierdo. Así, la capa más externa del cerebro es llena de cavidades denominadas córtex cerebral, es el responsable por el pensamiento, visión, audición, tacto, paladar, habla, escrita, etc.

El cerebro es el local donde ocurren los actos conscientes e inconscientes de la memoria, del raciocinio, de la inteligencia y de la imaginación; actuando también en el control de los movimientos voluntarios del cuerpo.

Cerebelo está ubicado en la parte posterior, debajo del cerebro; el cerebelo coordina los movimientos precisos del cuerpo, además de mantener el equilibrio. Además, regula el tono muscular, o sea regula el grado de contracción de los músculos en reposo.

Tronco Encefálico, ubicado en la parte inferior del encéfalo, el tronco encefálico conduce los impulsos nerviosos del cerebro para la médula espinal y viceversa.

También produce los estímulos nerviosos que controlan las actividades vitales como los movimientos respiratorios, las pulsaciones cardiacas y los reflejos, como la tos, el estornudo y la deglución.

La médula espinal se asemeja a un cordón de tejido nervioso ubicado dentro de la columna vertebral. En la parte superior está conectada al tronco encefálico. Su función es conducir los impulsos nerviosos del restante del cuerpo para el cerebro y coordinar los actos involuntarios como los reflejos (FAVARETTO; MERCADANTE, 2003).

\section{Sistema Nervioso Periférico}

El sistema nervioso periférico es formado por nervios que se originan en el encéfalo y en la médula espinal, constituido por las vías que conducen los estímulos al sistema nervioso central o que llevan la información hasta los órganos efectuadores. Su función es conectar el sistema nervioso central al resto del cuerpo. Existen dos tipos de nervios: los craneanos y los raquideanos (FAVARETTO; MERCADANTE, 2003).

Los Nervios Craneanos se distribuyen en 12 pares que salen del encéfalo y su función es transmitir mensajes sensoriales o motores, especialmente para las áreas de la cabeza y del cuello. Ya los Nervios Raquideanos son constituidos por 31 pares de nervios que salen de la médula espinal. Son formados de neuronas sensoriales que reciben estímulos del ambiente, y las neuronas motoras que llevan impulsos del sistema nervioso central para los músculos o para las glándulas. De acuerdo con su actuación, el sistema nervioso periférico puede ser dividido en sistema nervioso somático y sistema nervioso autónomo (FAVARETTO; MERCADANTE ,2003). 
El Sistema Nervioso Somático regula las acciones voluntarias, aquellas que están bajo el control de nuestra voluntad, así como regula la musculatura esquelética de todo el cuerpo. Mientras que el Sistema Nervioso Autónomo actúa de modo integrado con el sistema nervioso central y presenta dos subdivisiones: el sistema nervioso simpático, que estimula el funcionamiento de los órganos, y el sistema nervioso parasimpático que inhibe su funcionamiento (FAVARETTO; MERCADANTE, 2003).

Según Damásio (1996), el sistema nervioso central está conectado por medio de nervios a todos los mecanismos de desempeño del cuerpo y ese conjunto de nervios constituyen el sistema nervioso periférico. Tales nervios son responsables por transportar los impulsos del cerebro para las demás partes del cuerpo y viceversa.

Damásio (1996) destaca que, el cuerpo y el cerebro están conectados quimicamente por sustancias como las hormonas y los péptidos, que son liberados en el cuerpo y transportados para el cerebro por la corriente sanguínea y diversa de esas sustancias químicas que activan fibras nerviosas y viajan para la médula espinal, produciendo por diversas neuronas la forma en cadena de señales por numerosas sinapsis. Tal proceso será presentado y discutido brevemente a seguir.

\section{Fisiología y Morfología de las Células Neurológicas}

Los animales multicelulares presentan un sistema neurológico más avanzado y complejo, una vez que hay células receptoras que captan las informaciones del medio externo y que pueden localizarse a una considerable distancia de los órganos efectores. Para que eso ocurriera fue necesario el desarrollo de un sistema que transmita la información de forma rápida y efectiva por largas distancias. Para llenar este requisito, las células se especializaron y se organizaron para actuar como canales de comunicación entre los receptores sensoriales, de un lado y los efectores del otro. El conjunto de esas células es denominado de neuronas que comprende el sistema nervioso. Para conocer el funcionamiento del SNC es necesario identificar las estructuras que lo componen y su organización espacial (BRANDÃO; MARCUS LIRA, 2004). Con eso, sigue a continuación una discusión simplificada, con objetivo de promover la comprensión de la fisiología y morfología de las células neurológicas.

\section{Células Nerviosas}

Las neuronas son células comunes en todo y cualquier sistema nervioso existente en el reino animal, se estima que en el cerebro humano existan aproximadamente 15 billones de estas 
células, responsables por todas las funciones del sistema (KIERSZENBAUM; ABRAHAN, 2012).

Las neuronas se caracterizan como células nucleadas responsables por los impulsos nerviosos, altamente especializadas, dotadas de cuerpo celular y numerosos prolongamientos citoplasmáticos, capaces de captar y transmitir estímulos. El cuerpo celular de la neurona presenta núcleo grande y arredondado. Las mitocondrias son numerosas y el ergastoplasma es bien desarrollado. Las células nerviosas poseen grandes variaciones tanto en formato y tamaño. Se localizan principalmente en el encéfalo y médula espinal. Existen también las neuronas que quedan fuera del sistema nervioso central en la composición de los ganglios nerviosos localizados y agrupados en puntos específicos del cuerpo (JUNQUEIRA; CARNEIRO, 2012).

Existen diversos tipos de neuronas con diferentes funciones dependiendo de su localización, en su función se asemejan a un hilo conductor de electricidad y presenta estructura morfológica compuesta por tres componentes básicos: cuerpo celular, dendritos y axonio.

\section{Dendritos}

Los dendritos son ramificaciones que surgen del cuerpo celular que tiene la función de captar estímulos de otras neuronas, células epitaliales sensoriales o del medio ambiente, transmitiendo esas informaciones para el cuerpo celular. La mayoría de las neuronas poseen muchos dendritos y eso acaba por aumentar la superficie de la célula, que se afilan gradualmente hasta las extremidades, facilitando la captación y transmisión de los impulsos nerviosos (JUNQUEIRA; CARNEIRO, 2012).

\section{Cuerpo Celular}

También llamado de pericardio, el cuerpo celular es la parte de la neurona compuesta de núcleo esférico, cada núcleo posee un nucleolo y citoplasma rico en retículo endoplasmatico rugoso (RER). La cantidad de RER varía al tipo y la función de la neurona. El citoplasma es compuesto también por ribosomas, dispersos en el citoplasma, aparato de Golgi, localizados apenas alrededor del núcleo y mitocondrias que se presentan de forma moderada. El cuerpo celular además de ser considerado un centro trófico, o sea, parte de la célula nerviosa que se encuentra el núcleo y demás organelas, también recibe y transmite estímulos (inhibitorios o excitatorios) de otras neuronas (JUNQUEIRA; CARNEIRO, 2012). 


\section{Axonio}

El axonio es considerado la mayor prolongación de la célula nerviosa. Cada neurona contiene un axonio y se origina en una región de la célula, denominada cono de implantación, en sus extremidades hay ramificaciones en estructuras muy finas denominadas telodendro. En la mayor parte de los casos, esa estructura está envuelta por una vaina de mielina, que es formada por oligodendócritos o células de Schwann. Esa estructura no es continua por todo el axonio, ocurriendo áreas sin mielina, que son denominadas de nódulo de Ranvier. Entre la porción final de axonio y la superficie de otra célula, encontramos pequeños locales llamados de sinapsis. $Y$ en las sinapsis que son lanzadas sustancias (neurotransmisores) que permiten la transmisión del impulso nervioso de una célula para otra.

Morfológicamente las neuronas se clasifican en: Neuronas multipolares: poseen más de dos prolongamientos celulares, o sea, presencia de un axonio y varios dendritos. Neuronas bipolares: poseen un dendrito y un axonio. Función principal: transmisión de informaciones que fueron captados por órganos sensoriales como el olfato, visión y audición. Neuronas pseudo-unipolares: esos tipos de célula en particular poseen un cuerpo celular que luego se divide en dos, correspondiendo al dendrito y al axonio. En ese tipo de neurona, los impulsos nerviosos originados en los dendritos pueden ser transportados para el axonio sin necesidad de pasar por el cuerpo celular (JUNQUEIRA; CARNEIRO, 2012; FAVARETTO; MERCADANTE, 2003).

Las neuronas pueden ser clasificadas también por la función que desempeñan: Aferentes, sensitivas o sensoriales, poseen la función de recibir informaciones venidas del ambiente o desde afuera del cuerpo, y las transmiten para el sistema nervioso central a través de impulsos nerviosos; Eferentes o motores: estas células transmiten informaciones del sistema nervioso central y conducen impulsos nerviosos del sistema nervioso central para órganos efectores (músculos por ejemplo). Asociativos o interneuronas, poseen la función de conectar diversos tipos de neuronas, encontradas principalmente en el encéfalo y médula espinal (JUNQUEIRA; CARNEIRO, 2012; FAVARETTO; MERCADANTE, 2003).

\section{Células Neuroglia}

Existe otro importante elemento en el mantenimiento de la integridad de la neurona que es la glia o neuroglia. Las células gliales están distribuidas por el SNC y se diferencian de las neuronas por presentar estructura morfológica menor y no generar señales eléctricas.

Por muchos años, los investigadores y neurocientíficos creen que las neuronas eran las responsables por toda la comunicación en el cerebro y sistema nervioso, y que las células 
gliales, a pesar de ser nueve veces más numerosas que las neuronas, apenas los alimentaban. En las últimas décadas, técnicas de imagen vienen demostrando que las células gliales se comunican con las neuronas y unas con las otras. Ese proceso de comunicación permitió a las células gliales la capacidad de modificar las señales en las ranuras sinápticas entre las neuronas, ese fenómeno puede incluso influenciar el local de la formación de las sinapsis. Tales factores demuestran la importancia de las células gliales en el proceso de aprendizado y para la construcción de recuerdos, teniendo un papel efectivo en la recuperación de lesiones neurológicas (JUNQUEIRA; CARNEIRO, 2012; FAVARETTO; MERCADANTE, 2003).

Las células neuroglias se diferencian en forma y función, son: oligodendrócitos, astrócitos, células de Schwann, células ependimarias y microglia, (JUNQUEIRA; CARNEIRO, 2012).

\section{Oligodendrócitos}

Los Oligodendrócitos son responsables por la producción de la vaina de mielina, poseen la función de aislante eléctrico para las neuronas del SNC. Poseen prolongaciones que se enrollan alrededor de los axonios, produciendo la vaina de mielina (JUNQUEIRA; CARNEIRO, 2012; FAVARETTO; MERCADANTE, 2003).

\section{Astrócitos}

Ya los astrócitos son células de formato estrellado con varios procesos que irradian del cuerpo celular, presentan haces de filamentos intermediarios constituidos por la proteína fibrilar ácida de la glia, que refuerzan la estructura celular. Estas células ligan las neuronas a las capilares sanguíneas y la pia-máter. Existen los astrócitos fibrosos y los astrócitos protoplasmáticos. El primero es encontrado en la materia blanca y el segundo en la materia gris, teniendo un mayor número de prolongaciones que son más cortas y extremamente ramificadas. Estas células participan también de la regulación de diversas actividades neuronales. Pueden influir la actividad y la sobrevivencia de las neuronas, debido a su capacidad de controlar constituyentes del medio extracelular, absorber excesos localizados de neurotransmisores y sintetizar moléculas neuroactivas (JUNQUEIRA; CARNEIRO, 2012; FAVARETTO; MERCADANTE, 2003).

\section{Células de Schwann}

Las células de Schwann son células que presentan la misma función de los oligodendrócitos, sin embargo están localizadas alrededor de los axonios del sistema nervioso periférico, cada 
una de estas células forma una vaina de mielina en torno a un segmento de un único axonio (JUNQUEIRA; CARNEIRO, 2012; FAVARETTO; MERCADANTE, 2003).

\section{Ependimarias}

Mientras que las células Ependimarias son células epiteliales columnares que revisten los ventrículos del cerebro y el canal central de la médula espinal. En algunas regiones, estas células son ciliadas, facilitando el movimiento del líquido cefalorraquideano.

La microglia se caracteriza por ser células pequeñas y alargadas, con prolongaciones cortas e irregulares, son fagocitarias y derivan de precursores que alcanzan la médula osea atravez de la corriente sanguínea, representando el sistema mononuclear fagocitario do SNC. Participan también de la inflamación y reparación del sistema nervioso central, secretan también diversas citocinas reguladoras del proceso inmunológico y remueve los restos celulares que surgen en las lesiones del sistema nervioso central (JUNQUEIRA; CARNEIRO, 2012; FAVARETTO; MERCADANTE, 2003).

De este modo, entendemos que las células neurológicas son las estructuras que canalizan y propagan los estímulos recibidos, promoviendo la conducción de esos estímulos en respuestas para el propio organismo por medio de las sinapsis. Con eso, se evidencia que la salud de los sistemas nerviosos y sus funciones, especialmente su capacidad de aprendizaje, dependen del buen funcionamiento de las células neurológicas. La comprensión del sistema nervioso demuestra que las células neurológicas son protagonistas en el proceso de comando y control de todas las actividades y estímulos directos e indirectos del individuo, sin embargo falta entender como esa dinámica converge en la capacidad de aprendizaje, luego es importante analizar cuales son los aspectos del proceso de adquisición del conocimiento, que son los aspectos cognitivos (JUNQUEIRA; CARNEIRO, 2012; FAVARETTO; MERCADANTE, 2003).

\section{Aspectos Cognitivos}

La palabra cognición tiene su origen en el latín Cognitio, Cognitione, "conocimiento" (DICCIONARIO DE LATÍN FLORENCE, 2016). La palabra Cognitione tiene inicio en los escritos de Platón y Aristóteles. Cognición significa acto o proceso de adquirir conocimiento que envuelve atención, percepción, memoria, raciocinio, juicio, imaginación, pensamiento, 
lenguaje y acción. La interpretación del conocimiento no sigue un patrón descriptivo, pues la forma de recepción es subjetiva, distinguidos por la forma individual de análisis de la información, considerando la capacidad de aprendizaje y cognición de cada individuo (MATLIN, 2014).

La cognición va más allá de la adquisición de conocimiento, pues, es la forma como el cerebro recibe, aprende, recuerda y piensa sobre todas las informaciones captadas por los cinco sentidos. De esta forma, todo este conjunto de procesos mentales, es usado en el pensamiento, en la clasificación, reconocimiento y comprensión, para un posterior juicio de las acciones, por medio de raciocinio llevando al aprendizado de determinados sistemas en la resolución de problemas.

Todo este proceso es una forma de interacción de los seres vivos con sus semejantes y con el medio ambiente en que viven, sin perder su identidad existencial. Ella se inicia con la captación de los sentidos, seguida de la percepción. Es por lo tanto, un proceso de conocimiento que tiene como materia la información del medio ambiente y lo que ya se encuentra registrado en la memoria (MATLIN, 2004).

\section{Funciones Cognitivas}

Se atribuye el término neuropsicología al psicólogo Hebb (1904 - 1985) es la aplicación de la psicología y de la neurología, que estudia las relaciones entre el cerebro y el comportamiento humano. En otras palabras, la neuropsicologia actúa con más frecuencia en el estudio de las funciones mentales superiores. De ese modo, la neuropsicologia compone fuertemente el campo de las neurociencias, con énfasis en la neurociencia cognitiva.

Segundo Miotto et al., (2010), funciones superiores o ejecutoras se refieren a un conjunto de funciones mentales responsables por el procesamiento humano de la información. Integradas, dan las condiciones de interpretación, comportamiento, comunicación y relacionamento con si mismo, el mundo y con las otras personas. Pueden ser definidas como las habilidades de solución de problemas cotidianos, de forma general. Perjuicios en estas funciones generan alteraciones de comportamiento. Sobre las funciones cognitivas y las variables resultantes de nuestras experiencias sensoriales, captadas por nuestros sentidos (visuales, táctiles, olfativos, gustativos $\mathrm{y}$ auditivos), pueden volverse permanentes $\mathrm{o}$ desaparecer. Destacamos las siguientes funciones: memoria, percepción, atención, consciencia, raciocinio, conceptualización, lenguaje, pensamiento y abstracción.

\section{Memoria}


Según Luria (1981), la memoria tiene la función de recibir, analizar y almacenar informaciones, siendo responsable por el almacenamiento de nuestras experiencias, donde ocurre la retención y la evocación de esas experiencias, función compleja, pues es la facultad cognitiva que forma la base para el aprendizaje. Capacidad de registro, fijación y recordación de estímulos de cualquier naturaleza, retener con eficiencia los estímulos solo acontece cuando anteriormente identificado y comprendido. De esta forma, antes de memorizar los conceptos, el individuo debe comprenderlos.

\section{Percepción}

La percepción es la base para el desarrollo de la memoria, ocurre con la integración de estímulos y atribución de significados a los mismos, hay interpretaciones individuales acerca de diferentes objetos, a fin de atribuir significados en sus cualidades y relaciones.

\section{Atención}

La función atención, a pesar de que varios autores la consideran función derivada de la consciencia, está ligada a la percepción, por lo tanto, sería considerada un nivel inicial de procesamiento de los estímulos y se expresa a partir de la selección de ellos, se estima que la atención se desarrolla por fuerza de motivación, el acto que despierta el interés. Es el modo con que la mente selecciona y fija determinado estímulo por un periodo de tiempo variable, ese tiempo proviene del interés, de la motivación y desinterés del individuo y se trata de un fenómeno subjetivo. Funcionalmente, la atención está en la dependencia del sistema reticular activador, considerado una unidad neurológica responsable por regular el sueño y la vigilia y los estados mentales (LURIA, 1981), y del cortex pre-frontal (PAWLOWSKI et al., 2008). Instrumentos de evaluación psicológica y neuropsicológica tradicionalmente, evalúan la consciencia como una de las funciones superiores, teniendo en vista su relevancia e interacción con otros procesos mentales (PAWLOWSKI et al., 2008).

\section{Consciencia}

Según Block (2004), algunos filósofos dividen consciencia en consciencia fenomenal y consciencia de acceso, la primera es la experiencia propiamente dicha, y la otra es el procesamiento que vivenciamos durante nuestra experiencia. Consciencia una es el estado de estar consciente y consciencia de acceso se refiera a estar consciente de algo o alguna cosa. Consciencia es una cualidad psíquica, esto es, que pertenece a la esfera de la psiquis humana, por eso se dice también que es un atributo del espíritu, de la mente o del pensamiento 
humano. Ser consciente no es exactamente la misma cosa que percibirse en el mundo, pero ser en el mundo y del mundo; para eso, la intuición, la deducción son y la inducción toman parte.

La consciencia es la capacidad para mantener un organismo en estado de vigilia, estando así apto a desempeñar comportamientos motores, de comunicación y otros de forma voluntaria. La consciencia en este caso, significa estar despierto.

\section{Raciocinio}

Sobre el raciocinio, Block (2004) dice que es una forma cognitiva compleja, sucede en etapas más avanzadas del desarrollo del individuo. Es la forma de pensar a partir de la colecta de datos ofrecidos por la percepción, del levantamiento, hipótesis, selección y testes; ocurre envolviendo varias etapas de procesamiento de esos datos, resultando en la solución de problemas.

La conceptualización tiene la propiedad de categorizar o clasificar los objetos por medio de la abstracción de características que permite representar los mismos por el pensamiento. Significa por tanto, clasificar objetos de forma aislada y o combinadas.

\section{Lenguaje}

El lenguaje hace parte del proceso evolutivo del individuo, está conectada al desarrollo neurológico, de la inteligencia, de la afectividad, de la motricidad y de la socialización. En la obtención de la función del lenguaje, deben considerarse las diferencias y socialización de los individuos, bien como su nivel de maduración, experiencias y motivación. Ella permite construcción de consciencia social, adaptando el individuo a la realidad (BLOCK, 2004).

Respecto al pensamiento, varios autores a lo largo de los siglos, evidenciaron la importancia de su pensamiento en la construcción del individuo y de las sociedades. Según Piaget (1975), el pensamiento es constructo y constructivo del conocimiento. Gonsález Pecotch en su obra "Logosofía, Ciencia y Método", define pensamiento y pensar, como siendo respectivamente, una forma de proceso mental o facultad del sistema mental. Pensar permite a los seres, modelar el mundo y con eso lidiar con el de una forma efectiva y de acuerdo con sus metas, planos y deseos. Originalmente, pensar tiene un significado de evaluación de algo, conclusivamente el pensamiento tiene la incumbencia de evaluar la realidad.

El importante filósofo que contribuye para la historia del pensamiento, Descartes (1596 - 1650), decía que la esencia del hombre es pensar, "Soy una cosa que piensa, esto es, 
que duda, que afirma, que ignora, que ama, que odia, que quiere y que no quiere, que también imagina y que siente", "pienso, luego existo".

Tratándose de la abstracción, según Durozoi (2005), es una operación intelectual que consiste en aislar por ejemplo, en un concepto, un elemento a la exclusión de otros, del que se hace la abstracción. Como proceso de pensamiento, Langer (1953), en la obra Terminología Filosófica, la abstracción es el proceso de pensamiento en que las ideas son distanciadas de los objetos.

Por lo tanto, es posible afirmar que la cognición es el acto de adquirir conocimiento sobre el mundo a lo largo de la vida. Y ese aprendizaje está relacionado en la gran mayoría de las veces, directamente la adaptación al medio ambiente de cada individuo, sus necesidades fisiológicas y sociales.

Sin embargo, las tantas iniciativas dirigidas a la comprensión y funcionamiento de la mente y del desarrollo cognitivo carecen de ponderación, frente al hecho que mismo con ambientación favorable, sistema nervioso saludable, buena capacidad de adaptación, capacidad de aprendizaje y desarrollo cognitivo, existe un factor preponderante que es la capacidad innata de cada individuo. En este contexto, la dinámica, desarrollo, adaptación y aprendizaje pueden ser cuestionadas frente de individuos con grandes habilidades matemáticas, lingüísticas; niños con percepción musical refinada, que aprenden a tocar instrumentos solos.

Otro importante campo de estudio en el espectro del desarrollo cognitivo está relacionado con la pérdida o comprometimiento de la capacidad de aprendizaje. Como crear mecanismos que permitan la superación de factores limitantes del desarrollo cognitivo?

\section{Neuroplasticidad y Rehabilitación}

La respuesta a tal cuestionamento puede estar en la plasticidad cerebral o neuroplasticidad, que es la capacidad que el sistema nervioso central presenta de alteración de su perfil químico, estructural, más allá de sus funciones en respuesta a lesiones, ya que las células nerviosas centrales pueden regenerarse o hasta mismo formarse nuevamente, fenómeno denominado neurogénesis (HAASE; G.; LACERDA, S. 2004).

De acuerdo con Dennis (2000), la neuroplasticidad puede ser concebida y evaluada a partir de una perspectiva estructural (configuración sináptica) o funcional (modificación del comportamiento). La neuroplasticidad devolvió la esperanza para muchos pacientes con lesiones encefálicas, pues a la luz de este concepto, tales pacientes pueden ser rehabilitados dentro de ciertos límites, porque son dotados de flexibilidad y de plasticidad cerebral. 
Frente a la neuroplasticidad, Faveretto y Mercadante (2013), Hasse y Lacerda (2004), Junqueira y Carneiro (2012); describen que es necesario comprender que las células neurológicas y sus redes de conexiones sinápticas, en espacial las células glia, son primordiales para el proceso de rehabilitación, una vez que las células glia son modificables en función de la experiencia individual, o sea, del nivel de actividad y del tipo de estimulación recibida.

En ese contexto, en la búsqueda de resultados, investigadores vienen apuntando que cuanto más intensa y variada de la estimulación, más sinapsis serán formadas. Aunque ofrecer diferentes e innumerables estímulos sensoriales simultaneamente no garante el éxito de la rehabilitación, ya que el sistema nervioso central necesita recibir la misma información, repetidas veces, con cierto orden para poder integrar esas informaciones y volverse funcionales (HAASE, LACERDA, 2004).

Cotman y Berchtold (2002) apunta que el ejercicio físico es una forma de estímulo que induce alteraciones plásticas en el sistema nervioso central en animales de experimentación y potencializan esas alteraciones en largo plazo, promoviendo el aumento de niveles proteicos en las células neurológicas, fenómeno que está relacionada con los factores de crescimiento neuronal.

Como los procesos de reparación y reorganización del sistema nervioso central, comienzan a suceder luego después la lesión sufrida, la rehabilitación debe comenzar precozmente. En ese proceso regenerativo, las áreas cerebrales heridas o disfuncionales son sustituidas por áreas "vecinas" intactas que se ocuparon de las funciones "perdidas" a través del entrenamiento. Esa rehabilitación / regeneración solo es posible, debido a la permanente capacidad de aprender del cerebro.

De acuerdo con Hasse y Lacerda (2004) hay tres modelos conceptuales, no excluyentes, que son reconocidos en los procesos de rehabilitación neuropsicológica: restitución, sustitución y compensación. La teoría destaca que el proceso de rehabilitación ocurre de forma individual con los datos disponibles sobre los mecanismos lesionales, recuperación funcional y factores individuales relacionados a cada prognóstico.

El análisis de los aspectos plásticos del sistema nervioso nos permite relacionarlos a varios factores, como influencia del ambiente, a ejemplo el ambiente terapeútico que debe proveer condiciones adecuadas para el aprendizado o reaprendizado motor del paciente. El estado emocional, motivación y depresión, el nivel cognitivo, individuos que presentan menor déficit cognitivo, responden de manera más adecuada a la terapia, entre otros, que interfieren 
directa o indirectamente en la plasticidad del SNC y, consecuentemente, en la rehabilitación del paciente neurológico.

\section{CONCLUSIÓNS}

Muchos son los desafíos envueltos en la investigación de los mecanismos del proceso de aprendizaje y desarrollo cognitivo. Como punto pacífico, está el mantenimiento necesario de la salud del sistema nervioso y células neurológicos, dado que, desempeñan el papel principal en el proceso de comando y control de todas las actividades y estímulos directos e indirectos del individuo, por medio de las sinapsis. A partir de ese punto, sigue la comprensión de como cada individuo sintetiza los estímulos e impulsos sensoriales produciendo como resultado la adquisición del conocimiento.

Las literaturas permiten concluir que el proceso de desarrollo cognitivo está relacionado con la necesidad de adaptación, sean ellas fisiológicas o sociales de cada individuo en un ambiente determinado. Aunque tal teoría no finalice la cuestión en su totalidad, habiendo ponderaciones en las que cabe profundizar e investigar frente al hecho de que, mismo con ambientación favorable, sistema nervioso saludable, buena capacidad de adaptación, capacidad de aprendizaje y desenvolvimiento cognitivo, existe un factor preponderante que es la capacidad innata de cada individuo. Así, el contexto de la dinámica, desarrollo, adaptación y aprendizaje; no son aplicables a individuos con grandes habilidades.

La amplitud del tema presenta mayor relevancia del punto de vista de la neuroplasticidad que demuestra que las células neurológicas y sus redes y conexiones sinápticas, en especial las células glia, son primordiales para el proceso de rehabilitación, ya que las células glia son modificables en función de la experiencia individual, o sea, del nivel de actividad y del tipo de estimulación recibida.

Por lo tanto, el estudio de las células neurológicas y su interfaz en el proceso de aprendizaje de los seres vivos, demuestran gran relevancia a la luz de patologías relacionadas a la pérdida o comprometimiento de las capacidades cognitivas leves o de mayor gravedad como las patologías vinculadas a lesiones cerebrales, trastornos globales de desarrollo como el autismo, trastorno mentales graves como esquizofrenia, enfermedad de parkinson y enfermedad de alzheimer, tales pacientes depositan sus esperanzas en los avances de la neurociencia, neuropsicología y neuroplasticidad en la búsqueda de rehabilitación cognitiva y aumento de la calidad de vida y por que no, de la cura.

\section{REFERENCIAS}


BRANDÃO, M. L. - As bases biológicas do comportamento: introdução à neurociência. São Paulo, Editora Pedagógica e Universitária, ilus. Referencias, 223p. 2004.

CAPRA, F. A teia da vida: Uma nova compreensão cientifica dos sistemas vivos. Tradução de Newton Roberval Eichembeg. São Paulo: Cultrix, 2006.

O ponto de mutação. Tradução de Álvaro Cabral. São Paulo: Cultrix, 2012.

COSENZA, R.; GUERRA, L. B. Neurociência e educação: como o cérebro aprende. Porto Alegre: Artmed, 2011.

COTMAN, C. W.; BERCHTOLD, N. C. Exercise: A behavioral intervention to enchance brain health and plasticity. Trends in Neurosciences, v. 25, p. 295-301, 2002.

DAMÁSIO, A. O erro de Descartes: emoção, razão e o cérebro humano. Tradução de Dora Vicente e Georgina Segurado. São Paulo, Companhia das Letras, 1996.

DENNIS, M. Developmental plasticity in children: the role of biological risk, development, time, and reserve. Journal of Communication Disorders. ed. 33, p. 321-332, 2000.

FAVARETTO, J.A.; MERCADANTE, C. Biologia. Volume único, 2a ed., São Paulo: Moderna, 2003.

HAASE, V. G.; LACERDA, S. S. Neuroplasticidade, variação interindividual e recuperação funcional em neuropsicologia. Temas em Psicologia da SBP. v. 12, n. 1, p. $28-42,2004$.

JUNQUEIRA, L. C. U.; CARNEIRO, J. Histologia Básica. Rio de Janeiro. ed. 9, Elsevier, p. 560, 2012.

KIERSZENBAUM A.; ABRAHAM L. Histologia e biologia celular: introdução à patologia. Rio de Janeiro, p. 227, 2012.

MATLIN, M. W. Psicologia cognitiva. Rio de Janeiro, LTC, ed. 5, 2004. 
MIOTTO, E. C.; DE LUCIA, M. C. S.; SCAFF, M. (Orgs.). Neuropsicologia e as interfaces com as neurociências 1 reimpr. São Paulo: Casa do Psicólogo, 2010. cap. 16, p. 137-142.

ODUM, E. P. Fundamentos de ecologia. Lisboa, PT, Calouste Gulbenkian, 1988.

ODUM, E. P.; SANDERS, W. B. Fundamentals of Ecology. Philadelephia, 1959.

PAWLOWSKI, J.; FONSECA, R. P.; SALLES, J. F.; PARENTE, M. A. M. P.; BANDEIRA, D. R. Evidências de validade do Instrumento de Avaliação Neuropsicológica Breve Neupsilin. Arquivos Brasileiros de Psicologia. v. 60, n. 2, p. 101-116, 2008.

PIAGET, J. O nascimento da inteligência na criança. Rio de Janeiro, Zahar, 1975.

RICKLEFS, R. E. A Economia da Natureza. Editora Guanabara Koogan S.A., Rio de Janeiro, 1996.

SANVITO, W. L. Os comas na prática médica. São Paulo, Manole, 1978.

SNOWDON, C. O significado da pesquisa em Comportamento Animal. Pesquisa em Psicologia v. 4, ed.2, p. 365-373, 1999. 